\title{
A Study of Stroke Patients' Leisure Activities and Quality of Life
}

\begin{abstract}
This study was conducted in order to examine relationship between stroke patients' degree of satisfaction with leisure and quality of life according to their leisure activity types and whether they conducted leisure activities. A direct survey was performed from April 8 to May 3, 2013 on 92 inpatients and outpatients who received occupational therapy at hospitals located in Jeonju and Gunsan. A frequency analysis was carried out in order to look at the general characteristics of the subjects, their degree of participation in leisure activities, and their degree of satisfaction with leisure activities. A Pearson's coefficient was used to examine relationship between their degree of satisfaction and quality of life according to participation in leisure activities. Their degree of satisfaction according to participation in leisure activities was significantly higher when they took part in leisure activities such as handicraft activities, sports activities, or travel or tourism activities than when they did not perform any leisure activities. Their quality of life according to participation in leisure activities was higher when they conducted sports activities, outing activities, or tourism activities than when they did not. There was significant correlation between their degree of satisfaction with leisure and quality of life according to leisure activities.
\end{abstract}

Key words: Leisure Activity; Satisfaction; Stroke; Quality of Life

\author{
Hyun Hee Paek ${ }^{a}$, Eun Jin Seo ${ }^{b}$, Jeong \\ Ja Kim ${ }^{\mathrm{C}}$ \\ a'Gwangju University, Gwangju; ' ${ }^{\text {G }}$ unsan Medical \\ Center; Gunsan; "Howon University; Gunsan, \\ Korea
}

Received : 07 April 2014

Revised : 10 June 2014

Accepted : 20 September 2014

Address for correspondence

Jeong Ja Kim, PT, Ph.D

Department of Physical Therapy, Howon University, 64 Howondae3-ro, Gunsan, Korea

Tel: 82-10-4607-6568

E-mail: kotpt@hanmail.net

\section{INTRODUCTION}

There is an increase in ratio of elderly population and incidence rate of geriatric illness stroke due to the enhancement in health of people and lengthening of life expectancy followed by recent advancement in medicine(1). Stroke is one of various neurologic disorders caused by cerebrovascular damage and it bring about various stress disorders including hemiplegia, perceptual disturbance, sensory disturbance, memory impairment, language impairment, visual impairment, etc(2). Therefore, the range of daily and social activities narrows down and there is a decrease in number of leisure participations with difficulty to continue leisure activities conducted before stroke occurrence(3).

The leisure is one of occupational therapy domains proposed in OTPF(occupational therapy practice framework), an activity all people participate in (AJOT, 2008), and free time that is not labor time or basic time of daily lives(4). Also, it not only restore new strength for work with relief of mental and physical stress but also assists people to find emotional stability by relieving stress, frustration, conflict, disappointment, emotional anxiety, and others obtained from social life. Such benefits of leisure activities conform to ultimate objectives of welfare for the impaired that are normalization and social integration(5).

More attention is being paid to the leisure activities of the impaired accordingly with Article 24 Anti-discrimination in cultural and artistic activities and Article 25 Anti-discrimination in physical activities of "Anti-discrimination against and remedies for persons with disabilities act"(6). Psasmore and French(2003), Blacker(2008), and others suggested that the leisure is core element of occupation therapy among rehabilitation services and occupation therapy, particularly in the field of rehabilitation, shall play a role of enhancing the leisure activities $(7,8)$. 
However, priority is given to medical rehabilitation with focus on physical function in Korea. In case of stroke patients, they return to home or local society with progress in medical treatment to certain degree. Most of them stay at home without enthusiasm for continuous rehabilitation or interaction with people surrounding them. Therefore, it has become an element to exert negative effect on quality of life and worsen the status of patient(9).

Therefore, in regards to the impairment caused by the stroke, the objective of treatment shall lies in improvement in quality of life rather than complete recovery of symptom and systematic attention shall be paid on social participation, namely leisure activities, which have effect on quality of life so that they can exhibit their physical, mental, social capacity to the fullest(6).

Although there has been preceding studies on leisure activities of the disabled with spinal cord injury(10), leisure activities of disabled adult(4), leisure activities of physically disabled(11), leisure activities of visually disabled(12), and others, study by Yim(6) is the first domestic study on leisure activities of stroke patients. However, study by Yim(6) does not mention detailed and current status of leisure activities by stroke patients and there is a lack of study on life of quality relevant to leisure activities in field of occupation therapy regardless of the fact that leisure activity is actually the domain of occupational therapy.

Therefore, the purpose of this study is to examine the type of participation status of leisure activities, a domain of occupation therapy, with stroke patients as its subject and the influence of leisure activities on quality of life. The significance of this study lies in providing basic data to seek plans for more effective participation in leisure activities and enhancement in quality of life for stroke patients.

\section{METHODS}

\section{Subject}

The subject of this study is 92 adult inpatients and outpatients over 20 who are currently receiving occupational therapy from hospitals in Jeonju and Gunsan and can understand the contents of survey and questions of researcher. The subject has agreed to participate with understanding on objective and necessity of this study.

\section{Procedure}

After conducting preliminary survey with 10 stroke patients as its subject, survey question was revised and supplemented for easy understanding of subject and period of data collection was from 2013.04.08 to 2013.05.03. Data collection and analysis were conducted with direct survey by researcher with 92 stroke patients as its subject.

\section{Measuring Instruments}

\section{Type of leisure activities and degree of participation}

11 questions used in the study "Effect of leisure activity participation of disabled adult on life satisfaction" by Yun(4) were used in this study to examine the type and actual status of leisure activities of stroke patients. Drawn up questions are divided into 5 domains that are hobby $\cdot$ cultural activities, recreational $\cdot$ social activities, appreciation $\cdot$ viewing activities, health $\cdot$ sports activities, and amusement - tourism activities. In regards to each question, 1 point is given for 'almost every day', 2 points for '1 2 times per week', 3 points for '1 2 times per month', ' 4 points for '1 2 times per 6 months', and 5 points for 'almost never' based on Likert 5 point scale. The point for each question is added and lower points signify more participation in the leisure activities.

\section{Leisure satisfaction}

Scale used in the study "Effect of type and restriction of leisure participation by urban worker on leisure satisfaction and life satisfaction" by Song(13) was used in this study to measure the leisure satisfaction. It was composed of total 24 questions under 5 major category factors including 8 questions for psychological and physical satisfaction, 4 questions for environmental satisfaction, 4 questions for social satisfaction, 4 questions for relaxation satisfaction, and 4 questions for educational satisfaction. Then, it was measured with Likert 5 point scale from 1 point 'very likely' to 5 points 'very unlikely'. The lower points signify higher leisure satisfaction.

\section{Quality of Life}

Standardized quality of life scale WHOQOL-BREF developed by WHO was used in order to examine degree of quality of life(4). This scale is composed of total 26 questions including 24 questions in 4 domains 
that are 7 questions in physical domain, 6 questions in psychological domain, 3 questions for social domain, and 8 questions for life.environment domain and 2 questions for overall quality of life. Each question was measured with 5 point scale from 1 point 'very likely' to 5 point 'very unlikely' and back-calculation was conducted for 3 negative questions (question no. 3, 4, and 26). Higher sum signifies higher quality of life.

\section{Data Analysis}

SPSS 12.0 program was used for analysis on data collected in this study. In order to examine general trait of subject and participation \& satisfaction in leisure activities, frequency analysis was conducted. Independent sample t-test was conducted for leisure satisfaction and quality of life based on leisure activities. Pearson Correlation was conducted to examine the correlation between satisfaction and quality of life based on leisure activity participation.

\section{RESULTS}

\section{Characteristics general trait of subject}

Age distribution of subjects was $30.4 \%$ for 49 or younger, $10.9 \%$ for $50 \sim 59,23.9 \%$ for $60 \sim 69$, and $34.8 \%$ for 70 or older which occupied the most. In regards to gender, there was 50\% male and 50\% female. In regards to marriage status, $19.6 \%$ responded to be unmarried and $80.4 \%$ responded to be married which occupied the most. In regards to educational level, $43.5 \%$ was ${ }^{\ulcorner}$elementary graduation or lower level $13.0 \%$ was $\ulcorner$ middle school graduation $\lrcorner$, $30.4 \%$ was ${ }^{\top}$ high school graduation, and $13.0 \%$ was $\ulcorner$ college graduation or higher level」 thus elementary school graduate or lower occupied the most. In regards to type of stroke, it was $4.3 \%$ for ${ }^{\circ}$ cerebral embolism $_{\lrcorner}, 50.0 \%$ for $\ulcorner$ cerebral infarction $\lrcorner$, and $45.7 \%$ for $\ulcorner$ cerebral hemorrhage thus cerebral infraction occupied the most. In regards to the area of stroke, it was $60.9 \%$ for $\Gamma$ left side」 and $39.1 \%$ for $\ulcorner$ right side」 thus left side damage occupied the most(Table 1).

Table 1. The general characteristics of the subjects

\begin{tabular}{|c|c|c|}
\hline Characteristics & Classification & $\mathrm{n}(\%)$ \\
\hline \multirow{4}{*}{ Age } & 49 or younger & $28(30.4)$ \\
\hline & $50 \sim 59$ & 10(10.9) \\
\hline & $60 \sim 69$ & 22(23.9) \\
\hline & 70 or older & $32(34.8)$ \\
\hline \multirow{2}{*}{ Gender } & Male & $46(50.0)$ \\
\hline & Female & $46(50.0)$ \\
\hline \multirow{2}{*}{ Marriage Status } & Married & $74(80.4)$ \\
\hline & Unmarried & 18(19.6) \\
\hline \multirow{4}{*}{ Educational Level } & Elementary school or lower level & $40(43.5)$ \\
\hline & Middle school graduation & $12(13.0)$ \\
\hline & High school graduation & $28(30.4)$ \\
\hline & College graduation or higher level & $12(13.0)$ \\
\hline \multirow{3}{*}{ Type of Stroke } & Cerebral embolism & $4(4.3)$ \\
\hline & Cerebral infarction & $46(50.0)$ \\
\hline & Cerebral hemorrhage & $42(45.7)$ \\
\hline \multirow{3}{*}{ Area of Stroke } & Left side & $56(60.9)$ \\
\hline & Right side & 36(39.1) \\
\hline & Total & $92(100)$ \\
\hline
\end{tabular}




\section{Characteristic general trait of subject type of leisure activity and degree of participation}

As a result of investigating degree of participation based on leisure activity type of stroke patients, it was $19.6 \%$ for participation of $1 \sim 2$ or more times per week, $10.9 \%$ for participation of $1 \sim 2$ or less times per 6 months, and $69.6 \%$ for no activity in regards to reading, collection, handicraft, sewing, woodwork, craft activities thus no activity occupied the most. In regards to making special food or snacks, decorating the house interior, it was $8.7 \%$ for $1 \sim 2$ or more times per week, $6.5 \%$ for $1 \sim 2$ or less times per 5 months, $84.8 \%$ for no activities thus no activity occupied the most. In regards to listening to radio and watching TV, it was $97.8 \%$ for $1 \sim 2$ or more times per week, $2.2 \%$ for $1 \sim 2$ or less times per 6 months, and $0.0 \%$ for no activity thus 1 2 or more times per week occupied the most. In regards to computer game, electronic game, Korean chess, the game of go, and card game, it was $26.1 \%$ for $1 \sim 2$ or more times per week, $4.3 \%$ for 1 2 or less times per 6 months, and $69.6 \%$ for no activity thus no activity occupied the most. In regards to traditional play, conversing with acquaintances, and religious activities, it was $58.7 \%$ for $1 \sim 2$ or more times per week, $4.3 \%$ for $1 \sim 2$ or less times per 6 months, and $37.0 \%$ for no activity thus no activity occupied the most. In regards to cultural activities such as going to concerts, watching sports, and going to art museums and museums, it was $2.2 \%$ for $1 \sim 2$ or more times per week, $19.6 \%$ for $1 \sim 2$ or less times per 6 months, and $78.3 \%$ for no activity thus no activity occupied the most. In regards to watching plays, movie appreciation, video appreciation, and shopping, it was $6.5 \%$ for $1 \sim 2$ or more times per week, $23.9 \%$ for $1 \sim 2$ or less times per 6 months, and $69.6 \%$ for no activity thus no activity occupied the most. In regards to diverse sports activities such as soccer, basketball, volleyball, swimming, table tennis, and tennis, it was $13.0 \%$ for $1 \sim 2$ or more times per week, $4.3 \%$ for $1 \sim 2$ or less times per 6 months, and $82.6 \%$ for no activity thus no activity occupied the most. In regards to climbing, stroll, hiking (in a wheelchair, riding a bicycle), it was $28.3 \%$ for $1 \sim 2$ or more times per week, $2.2 \%$ for $1 \sim 2$ or less times per 6 months, and $69.6 \%$ for no activity thus no activity occupied the most. In regards to outdoor activities like going to an amusement park or a zoo, it was $17.4 \%$ for $1 \sim 2$ or more times per week, $17.4 \%$ for $1 \sim 2$ or less times per 6 months, and $65.2 \%$ for no activity thus no activity occupied the most. In regards to travel or tourism activities, it was $2.2 \%$ for $1 \sim 2$ or more times per week, $21.7 \%$ for $1 \sim 2$ or less times per
6 months, and $76.1 \%$ for no activity thus no activity occupied the most(Table 2).

\section{Leisure satisfaction based on leisure activities}

As a result of investigating the leisure satisfaction based on leisure activities of stroke, the leisure satisfaction was significantly higher in case of conducting reading, collection, handicraft, sewing, woodwork, and craft activities ( $p<.01)$, diverse sports activities such as soccer, basketball, volleyball, swimming, table tennis, and tennis ( $\mathrm{p}<.01$ ), outdoor activities like going to an amusement park or a zoo $(p<.01)$, and travel or tourism activities $(p<.01) \mathrm{com}^{-}$ pared to not conducting such activities(Table 3 ).

\section{Quality of life based on leisure activities}

As a result of investigating the quality of life based on leisure activities of stroke patients, the quality of life was significantly higher when conducting diverse sports activities such as soccer, basketball, volleyball, swimming, table tennis, and tennis ( $p<.01)$, outdoor activities like going to an amusement park or a zoo $(p<.05)$, and travel or tourism activities $(p<.01)$ compared to not conducting such activities(Table 4).

\section{Correlation between leisure satisfaction and quality of life}

As a result of examining the correlation between leisure satisfaction and quality of life based on leisure activities of stroke patients, leisure satisfaction and quality of life are presented to have statistically significant negative correlation ( $\mathrm{p}<.01)$ (Table 5). 
Table 2 Types of leisure activities and degree of participation in leisure activities

\begin{tabular}{|c|c|c|c|}
\hline \multirow[b]{2}{*}{ Types of Leisure Activities } & \multicolumn{3}{|c|}{ Degree of Participation } \\
\hline & $\begin{array}{l}\text { 1 2 or more } \\
\text { times per week }\end{array}$ & $\begin{array}{l}\text { 1 2 or less times } \\
\text { per six months }\end{array}$ & No activity \\
\hline Reading, collection, handicraft, sewing, woodwork, craft & 18(19.6) & 10(10.9) & $64(69.6)$ \\
\hline Making special food or snacks, decorating the house interior & $8(8.7)$ & $6(6.5)$ & $78(84.8)$ \\
\hline Listening to the radio, watching television & 90(97.8) & $2(2.2)$ & $0(0.0)$ \\
\hline Computer/electronic/card game, Korean chess, the game of go & $24(26.1)$ & $4(4.3)$ & $64(69.6)$ \\
\hline Traditional play, conversing with acquaintances, religious activities & $54(58.7)$ & $4(4.3)$ & $34(37.0)$ \\
\hline $\begin{array}{l}\text { Cultural activities such as going to concerts, watching sports going } \\
\text { to art museums and museums }\end{array}$ & 2(2.2) & 18(19.6) & 72(78.3) \\
\hline Watching plays, movie appreciation, video appreciation, shopping & $6(6.5)$ & 221(23.9) & $64(69.6)$ \\
\hline $\begin{array}{l}\text { Diverse sports activities such as soccer, basketball, volleyball } \\
\text { swimming, table tennis, and tennis }\end{array}$ & 12(13.0) & $4(4.3)$ & $76(82.6)$ \\
\hline Climbing, stroll, hiking (in a wheelchair, riding a bicycle) & $26(28.3)$ & $2(2.2)$ & $64(69.6)$ \\
\hline Outdoor activities like going to an amusement park or a zoo & 16(17.4) & 16(17.4) & $60(65.2)$ \\
\hline Travel or tourism activities & $2(2.2)$ & $20(21.7)$ & $70(76.1)$ \\
\hline Total & & $92(100)$ & \\
\hline
\end{tabular}

Table 3. The subjects' degree of satisfaction with leisure according to whether they conduct leisure activities $n(\%)$

\begin{tabular}{lccc}
\hline \multicolumn{1}{c}{ Types of Leisure Activities } & \multicolumn{3}{c}{ Satisfaction of leisure } \\
\cline { 2 - 4 } & $\begin{array}{c}\text { No activity } \\
\text { M } \pm \text { SD }\end{array}$ & $\begin{array}{c}\text { Activities } \\
\text { M } \pm \text { SDt }\end{array}$ & t \\
\hline Reading, collection, handicraft, sewing, woodwork, craft & $75.00 \pm 22.36$ & $57.21 \pm 16.53$ & $3.00^{* *}$ \\
Making special food or snacks, decorating the house interior & $70.63 \pm 22.00$ & $64.62 \pm 23.88$ & .69 \\
Listening to the radio, watching television & $96.00 \pm 00.00$ & $69.00 \pm 22.06$ & .23 \\
Computer/electronic/card game, Korean chess, the game of go & $72.64 \pm 22.24$ & $63.26 \pm 21.38$ & 1.35 \\
Traditional play, conversing with acquaintances, religious activities & $71.00 \pm 21.77$ & $68.67 \pm 22.78$ & .34 \\
Cultural activities such as going to concerts, watching sports going & $70.91 \pm 22.68$ & $64.80 \pm 20.63$ & .76 \\
to art museums and museums & $72.75 \pm 22.64$ & $61.53 \pm 19.49$ & 1.57 \\
Watching plays, movie appreciation, video appreciation, shopping & $74.83 \pm 21.29$ & $48.00 \pm 8.70$ & $5.90^{* *}$ \\
Diverse sports activities such as soccer, basketball, volleyball & $73.00 \pm 23.70$ & $61.78 \pm 16.41$ & 1.84 \\
swimming, table tennis, and tennis & & $3.43^{* *}$ \\
Climbing, stroll, hiking (in a wheelchair, riding a bicycle) & $76.43 \pm 22.04$ & $56.75 \pm 16.34$ & $5.98^{* *}$ \\
Outdoor activities like going to an amusement park or a zoo & $73.97 \pm 22.16$ & $55.63 \pm 16.18$ & \\
Travel or tourism activities & & & \\
\hline
\end{tabular}


Table 4. The subjects' quality of life according to whether they conduct leisure activities

\begin{tabular}{|c|c|c|c|}
\hline \multirow{2}{*}{ Types of Leisure Activities } & \multicolumn{3}{|c|}{ Quality of Life } \\
\hline & $\begin{array}{l}\text { No activity } \\
M \pm S D\end{array}$ & $\begin{array}{l}\text { Activities } \\
M \pm S D t\end{array}$ & $t$ \\
\hline Reading, collection, handicraft, sewing, woodwork, craft & $71.18 \pm 15.75$ & $73.21 \pm 19.34$ & -.37 \\
\hline Making special food or snacks, decorating the house interior & $71.31 \pm 16.38$ & $74.12 \pm 19.30$ & -.42 \\
\hline Listening to the radio, watching television & $72.00 \pm 00.00$ & $71.80 \pm 16.92$ & -.01 \\
\hline Computer/electronic/card game, Korean chess, the game of go & $68.90 \pm 17.31$ & $77.80 \pm 14.15$ & -1.72 \\
\hline Traditional play, conversing with acquaintances, religious activities & $70.55 \pm 17.65$ & $72.60 \pm 16.38$ & -.40 \\
\hline $\begin{array}{l}\text { Cultural activities such as going to concerts, watching sports going } \\
\text { to art museums and museums }\end{array}$ & $70.66 \pm 17.08$ & $75.90 \pm 15.52$ & -.87 \\
\hline Watching plays, movie appreciation, video appreciation, shopping & $69.36 \pm 17.26$ & $78.00 \pm 14.14$ & -1.60 \\
\hline $\begin{array}{l}\text { Diverse sports activities such as soccer, basketball, volleyball } \\
\text { swimming, table tennis, and tennis }\end{array}$ & $69.35 \pm 15.05$ & $81.88 \pm 20.32$ & $-2.09^{*}$ \\
\hline Climbing, stroll, hiking (in a wheelchair, riding a bicycle) & $69.87 \pm 15.59$ & $76.21 \pm 18.94$ & -1.18 \\
\hline Outdoor activities like going to an amusement park or a zoo & $66.26 \pm 14.76$ & $82.18 \pm 15.56$ & $-3.42^{* *}$ \\
\hline Travel or tourism activities & $68.34 \pm 17.52$ & $82.81 \pm 6.35$ & $-4.10^{* *}$ \\
\hline
\end{tabular}

${ }^{*} \mathrm{p}<.05,{ }^{* *} \mathrm{p}<.01$

Table 5. Correlation between the Subjects' Degree of Satisfaction with Leisure Activities and Quality of Life.

\begin{tabular}{lcc}
\hline & Leisure Satisfaction & Quality of Life \\
\hline Leisure satisfaction & 1 & $-.424^{* *}$ \\
Quality of Life & $-.424^{* *}$ & 1 \\
\hline${ }^{* *} p<.01$ & &
\end{tabular}

\section{DISCUSSION}

Correlation between leisure satisfaction and quality of life based on type and conduct of leisure activities was examined with 92 stroke patients as its subject. As a result of investigating the degree of participation based on type of leisure activities for stroke patients, 1 2 or more times per week occupied the most for listening to the radio and watching television presenting $97.8 \%$ and participation of $1 \sim 2$ or more times per week was presented to be high for traditional play, conversing with acquaintances, and religious activities as well presenting $58.7 \%$ but it was suggested that over 50\% did not participate at any leisure activity. In a study on leisure satisfaction of patients with spinal cord injury by Lee(10), the degree of participation was presented to high in order of listening to radio and watching television for
$87.2 \%$, computer game, Korean chess, the game of go, and card game for 30.9\%, and traditional play, conversing with acquaintances, and religious activities for $28.7 \%$ conforming to the result of this study. As a result of investigating leisure satisfaction based on leisure activity of stroke patients, the leisure satisfaction of people participating in reading, collection, handicraft, sewing, woodwork, and craft activities, diverse sports activities such as soccer, basketball, volleyball, swimming, table tennis, and tennis, outdoor activities like going to an amusement park or a zoo, and travel or tourism activities was presented to be high. It was revealed that satisfaction was not high for listening to radio or watching television although many people participate in such activities but it was high for sports activities or travel. Just as healthy people take pleasure in sports activities or travel, stroke patients also do have sound mind and emotion although they may be disabled physically. Physically disabled is constantly exposed to stress, tension, and isolation due to social bias and thus it is considered that satisfaction of people participating in sports activities is high because such emotion can be relieved through sports(15).

As a result of investigating the quality of life based on leisure activities of stroke patients, quality of life was significantly high for those who participate in diverse sports activities such as soccer, basketball, 
volleyball, swimming, table tennis, and tennis, outdoor activities like going to an amusement park or a zoo, and travel or tourism activities. It can be considered that sports activities are closely related to quality of life since not only energy for life but also sound mind can be restored by participating in sports activities. In a study by Yim(5), it was revealed that quality of life is higher for stroke patients who participate in leisure activities compared those who do not participate in such activities. Although the subject is different, the result of study by Choi(16) which suggests leisure and sports activities of elderly has significant influence on quality of life supports the result of this study. Also, study by Jeong(17) suggests that leisure activities have major influence on quality of life since group of stroke patients which participated in health program presented higher quality of life compared to a group which did not participated in such program.

As a result of examining the correlation between leisure satisfaction and quality of life based on leisure activities of stroke patients, leisure satisfaction and quality of life presented statistically significant negative correlation. This signifies that high quality of life is followed by high leisure satisfaction. Leisure satisfaction was higher for people who conduct more active leisure activities compared to those who spend idle time. Since active leisure activity participation of stroke patient can fundamentally enhance their quality of life, diverse approaches shall be taken to encourage active participation in leisure activities. The limitation of this study lies in the fact that the study was conducted with stroke patient in particular area as its subject and it is difficult to generalize the result since the samples of research subject is small. Also, the type of leisure activities based on degree of research subjects' impairment has not been examined. Therefore, a study on type of leisure activities and quality of life based on recognition and paralysis status of stroke patients shall be conducted in the future.

\section{CONCLUSION}

Leisure activity participation of stroke patient enhances quality of life. Therefore, active support and education shall be implemented to encourage more participation in leisure activities.

\section{REFERENCES}

1. M. R. Goulding, M. E. Rogers, \& S. M. Smith. Public health and aging: Trends in aging-United States and worldwide. J of the American Medical Association. 2003; 28(9): 1371-1373.

2. M. Zwecker, S. Levenkrohn, Y. Fleisig, G. Zeiling, A. Ohry, \& A. Adunsky. Mini-Mental State Examinnation, cognitive FIM instrument, and the Lowenstein Occupational Therapy Cognitive Assessment: relation to functional outcome of stroke patients. Arch Phys Med Rehabil., Mar. 2002; 83(3): 342-345.

3. Y. Lee, \& S. Hong. A Study on the Art Therapy with Game Activity for the Enhancement of the Hand Function and Human Relationship of the Stroke Elderly. Korea J of Counseling. 2009; 10(1): 1-16.

4. E. Yoon. Influence of leisure activities participation by the adult disabled on life satisfaction : based on the disabled with physical disabilities and brain disorder. Catholic University A masters degree 2007.

5. G. Im. A Study on the Participation of Disabled People with Stroke in Leisure Programs and Their Quality of Life. Catholic University A masters degree 2006.

6. Ministry for Health. Welfare and Family Affairs. Survey of Disabled 2008.

7. A. Passmore, \& D. French. The nature of leisure in adolescence: A focus group study. Brirish $J$ of Occupational Therapy. 2003; 66(9): 419-426.

8. D. Blacker, L. Broadhurst, \& L. Teixeira. The role of occupational therapy in leisure adaptation with complex neurological disability: A discussion using two case study example. Neurorehabilitation. 2008; 23(1): 313-319.

9. H. Cheng. Study on the Family Stress of Stroke Patient. Taejon University A masters degree 2000.

10. W. Lee. Influence of Leisure Activity by the Spinal Cord Injury on Quality of Life. Daegu University Graduate School of Rehabilitation Science. 2011.

11. J. Jang. Influence of Leisure Activities Participation by Physical Disabled on Life Satisfaction. Kyungpook University A masters degree 2011.

12. M. Jung. Effect of Leisure Constraints and Leisure Motivation on Leisure Satisfaction of People With Visual Impairment. Dankook University A masters degree 2013. 
13. W. Song. The influence of participation patterns and constraints on urban workers' leisure and life satisfaction Yonsei University A masters degree 2004.

14. World Health Organization. WHOQOL study protocol. Geneva: World Health Organization. 1993.

15. H. Choi. A research about The Plan for Activating of Seriously Handicapped People's Activities during Leisure Time. Pusan University A masters degree 2001.
16. H. Choi. The Effect of participation in leisure sport on the quality of life for older adults: Focused on older adults in Goyang city. Kangnam University Graduate School Social Welfare 2011.

17. J. Chung. A Study on the Participation of Poststroke Disabled Person in Health Promotion Programs and their Quality of Life. Ewha Women's University A masters degree 2000. 